\title{
Discovery of new Toxoplasma gondii antigenic proteins using a high throughput protein microarray approach screening sera of murine model infected orally with oocysts and tissue cysts
}

\author{
Mert Döşkaya 1* (D, Li Liang², Aarti Jain², Hüseyin Can³, Sultan Gülçe Iz ${ }^{4}$, Philip Louis Felgner²,
} Aysu Değirmenci Döşkaya' ${ }^{1}$, David Huw Davies ${ }^{2}$ and Adnan Yüksel Gürüz ${ }^{1}$

\begin{abstract}
Background: Toxoplasma gondii is an obligate intracellular protozoan parasite that causes congenital toxoplasmosis, as well as other serious clinical presentations in immune compromised humans. The parasite has also been recently linked to behavioral diseases in humans and other mammalian hosts. New antigens are being evaluated to develop a diagnostic kit for the diagnosis of acute infection or a protective vaccine.

Methods: In this study, we have focused on the discovery of new antigenic proteins from T. gondii genomic data using a high throughput protein microarray screening. To date, microarrays containing $>2870$ candidate exon products of $T$. gondii have been probed with sera collected from patients with toxoplasmosis. Here, the protein microarrays are probed with well-characterized serum samples from animal models administered orally with oocysts or tissue cysts. The aim was to discover the antigens that overlap in the mouse profile with human antibody profiles published previously. For this, a reactive antigen list of 240 antigens recognized by murine IgG and IgM was identified using pooled sera from orally infected mice.

Results: Analyses of screening data have identified plenty of antigens and showed strong immunogenicity in both mouse and human antibody profiles. Among them, ROP1, GRA2, GRA3, GRA4, GRA5, GRA6, GRA7, GRA8, GRA14, MIC1, MIC2 and MAG1 have shown strong immunogenicity and used as antigen in development of vaccines or serological diagnostic assays in previous studies.
\end{abstract}

Conclusion: In addition to the above findings, ROP6, MIC12, SRS29A and SRS13 have shown strong immunogenicity but have not been tested in development of a diagnostic assay or a vaccine model yet.

Keywords: Toxoplasma gondii, Oocysts, Sporozoite, Tissue cyst, Bradyzoite, Protein microarray, Antigen discovery, Vaccine, Diagnostics

\footnotetext{
* Correspondence: mert.doskaya@ege.edu.tr

'Department of Parasitology, Vaccine Research and Development Laboratory,

Ege University Faculty of Medicine, Bornova/Izmir, Turkey

Full list of author information is available at the end of the article
}

(C) The Author(s). 2018 Open Access This article is distributed under the terms of the Creative Commons Attribution 4.0 International License (http://creativecommons.org/licenses/by/4.0/), which permits unrestricted use, distribution, and reproduction in any medium, provided you give appropriate credit to the original author(s) and the source, provide a link to the Creative Commons license, and indicate if changes were made. The Creative Commons Public Domain Dedication waiver (http://creativecommons.org/publicdomain/zero/1.0/) applies to the data made available in this article, unless otherwise stated. 


\section{Background}

Toxoplasma gondii is a protozoan parasite that has a widespread distribution worldwide among humans and animals [1]. The importance of this intracellular parasite comes from the clinical presentations formed in the fetus and in immune compromised patients. Infection of women early in pregnancy is associated with an increased risk of congenital toxoplasmosis in utero and may become lethal by dissemination to vital organs such as brain, heart or lungs. This may also occur in immunocompromised adults by therapeutic immunosuppression, such as in cancer chemotherapy or organ transplantation [1]. Recently, T. gondii has also been linked to behavioral syndromes such as schizophrenia or bipolar disorder [2].

The transmission of toxoplasmosis mainly occurs through contaminated water and foods [1]. Felidae cats are definitive hosts in which the production of oocysts occurs. Cats disseminate resistant oocysts in their feces that can be contagious up to 18 months in the environment. Humans, as well as other intermediate hosts, are often infected via domestic cats, but can also become infected by ingestion of tissue cysts in raw or under-cooked meat prepared from infected hosts.

Due to ease of transmission and resistance of oocysts in the environment, $1 / 3$ of humans are estimated to be infected with T. gondii worldwide [3]. The rate of toxoplasmosis among pregnant women range between 37$58 \%$ in Europe [3], compared to $10.8 \%$ in the USA. [4]. In the USA, each year 400-4000 infants are estimated to be born with congenital toxoplasmosis, and up to 1.26 million cases of ocular toxoplasmosis are reported [3]. In addition, $T$. gondii oocysts are classified as a category $\mathrm{B}$ bioterrorism agents owing to a potential threat to water safety [5], as demonstrated by tainted water outbreaks that occurred in British Columbia, that affected 7718 people [6], Santa Isabel do Ivai of Brazil that affected hundreds of people [7], Coimbatore, India that affected 178 people [8], and Izmir that affected 171 Air Force Academy recruits [9].

In addition to being the definitive host for $T$. gondii, abundance and close proximity of cats as a companion species in human populations plays an important role in transmission of infections to humans. According to the American Veterinary Medical Association (AVMA) and the European pet food industry Federation (FEDIAF) the total number of domestic cats in the USA is over 74 million, or approximately 1 cat per family of 4 , and 74 million in the European Union [10, 11].

During acute toxoplasmosis in pregnant women, fetus can get infected by $T$. gondii and congenital toxoplasmosis may occur. The first problem is misdiagnoses of acute toxoplasmosis in pregnant women during the first trimester due to the insufficiency of serological assays that cannot discriminate acute infection and chronic infection. Antigens specific for acute infection can be used in these serological assays for timely diagnosis of the disease. The other problem is that an efficient vaccine that can protect pregnant women against toxoplasmosis does not exist. Current diagnostic antigens that are used to develop diagnostic assays or vaccine candidate antigens are almost always selected randomly and/or based on biological properties such as being a surface protein, having a role in pathogenesis, or high immunogenicity $[12,13]$. In this new era of advanced technology, methods to select antigens should specifically take advantage of recent advances such as in silico analysis and novel in vitro and in vivo immunoscreens for the generation of new antigens. The present study addresses this bottleneck in selection of antigenic proteins against toxoplasmosis using a high throughput protein microarray screening approach [14]. Initially, we have generated protein microarray chips containing 2870 candidate exon products of $T$. gondii. Then, we probed them with well grouped human sera [(i) acute (IgM- positive and low avidity IgG); (ii) chronic with IgM persistence (IgM-positive and high avidity IgG); (iii) chronic (IgM-negative and high avidity IgG); and toxoplasmosis negative] [15, 16]. There was a shortcoming in this approach that experimental infections are not possible in humans and we could not determine the antigens that were present at the beginning of the infection. This knowledge was important since these antigenic proteins can be very important to develop a diagnostic assay or a vaccine.

Following the two protein array studies in human toxoplasmosis, here we report a comprehensive in vivo study in a mouse model screened by protein microarrays. Mouse is an intermediate host with immune response similar to humans. For this purpose, two mouse groups were infected orally with oocysts and tissues cysts mimicking natural route of infection. Sera were collected prior to infection (Day 0 ) and at 1, 2, 3, 6, 10, 15, 40 and 120 days after infection. Then, protein microarray slides were probed with these sera to identify immunodominant exon products present in acute and chronic murine toxoplasmosis. Infecting the mouse groups with oocysts or tissue cysts also gave us the opportunity to determine the dominant antigens presented via the fecal-oral and ingestion routes of entry (i.e. mimicking natural route of infection). 


\section{Methods}

\section{Animals}

Six to eight weeks-old female Swiss outbred mice were obtained from the Bornova Veterinary Control Institute Animal Production Facility. Toxoplasma gondii oocysts were obtained from a recently weaned kitten, approximately 3-4 months-old.

During in vivo studies, mice and cat were housed in different rooms under standard and suitable conditions. Specifically, rooms had ambient temperature and humidity, adequate light cycle, and diet was specific for each animal type. All animals were checked for humane endpoints every day such as rapid weight loss more than $\sim 20 \%$ of gross body weight, inability to assess water or food, or loss of skin elasticity indicative of dehydration.

\section{Obtaining tissue cysts and oocysts}

A kitten was fed with $T$. gondii PRU strain tissue cysts obtained from mouse brain as described [17]. Initially, brains of previously infected mice were extracted under sterile conditions and homogenized in approximately 2 $\mathrm{ml}$ sterile $0.9 \% \mathrm{NaCl}$ containing penicillin $(10 \mathrm{U} / \mathrm{ml})$, streptomycin $(10 \mu \mathrm{g} / \mathrm{ml})$ and gentamicin $(2 \mu \mathrm{g} / \mathrm{ml})$ using an injector with $20 \mathrm{G} 1$ " $(0.9 \times 25 \mathrm{~mm})$ needle. The tissue cysts were counted by hemocytometer under phase contrast microscope (Nikon) and the remaining homogenate was used to passage the strain in vivo.

To feed the kitten, a part of the infected mouse brain was crushed between cover glass and slide and tissue cysts were examined under phase contrast microscope. The remaining brain with tissue cysts was fed to the cat. Before feeding the kitten, the presence of oocysts in kitten stool was examined using sucrose flotation technique as described [17].

After feeding, the feces of the kitten were collected daily and oocysts were purified as described [17-19]. Briefly, $\sim 10 \mathrm{~g}$ of feces were softened by adding to a 50 $\mathrm{ml}$ tube, filled with tap water and incubated for $2 \mathrm{~h}$ at room temperature. The tap water was discarded and approximately $50 \mathrm{ml}$ sucrose/phenol solution (53 g sucrose, $0.8 \mathrm{ml}$ liquid phenol, $100 \mathrm{ml}$ tap water) was added to the softened feces, and slowly emulsified using a spatula. Next, the homogenate was filtered through two layers of sterile gauze and centrifuged at $400 \times g$ for 10 min. Then, $500 \mu \mathrm{l}$ supernatant from the top of the tube was collected and mixed with $4.5 \mathrm{ml} 2 \% \mathrm{H}_{2} \mathrm{SO}_{4}$ to stimulate sporulation. The oocysts were then incubated at room temperature for 3-5 days and checked for sporulation by microscopy. As the oocysts sporulated, 3 ml of $1 \mathrm{~N} \mathrm{NaOH}$ was added to the mixture to stop stimulation.

For purification of oocysts, $4 \mathrm{ml}$ of $2.2 \mathrm{M}$ sucrose solution was mixed with the sporulated oocysts and then 5 ml distilled $\mathrm{H}_{2} \mathrm{O}$ was carefully overlaid and centrifuged at $1200 \times g$ for $20 \mathrm{~min}$. Supernatant containing oocysts was collected without disturbing the sucrose solution, and $4 \mathrm{ml}$ of $2.2 \mathrm{M}$ sucrose solution was mixed with the supernatant again. Then, $5 \mathrm{ml}$ distilled $\mathrm{H}_{2} \mathrm{O}$ was carefully overlaid and centrifuged at $1200 \times g$ for $20 \mathrm{~min}$. The supernatant containing oocysts was collected, resuspended in $50 \mathrm{ml}$ of distilled water, and centrifuged at $2000 \times g$ for $10 \mathrm{~min}$. About $1-2 \mathrm{ml}$ of the supernatant collected from the top of the tube was mixed with an equal volume of sterile $0.9 \% \mathrm{NaCl}$. The resulting purified oocysts were quantified by hemocytometer under phase contrast microscopy and immediately used to infect mice.

\section{Infection of mice and collection of sera}

Two groups of Swiss outbred mice $(n=10)$ were administered orally with fresh 8-10 sporulated oocysts and 10-15 tissue cysts using a stainless steel curved feeding needle (Harvard Apparatus). Serum samples were collected by tail bleeding from each anesthetized mouse prior to inoculation (day 0 ) and on day $1,2,3,6,10,15$, 40 and 120 after infection. On day 120, mice were euthanized and brains were homogenized in approximately 2 $\mathrm{ml}$ sterile $0.9 \% \mathrm{NaCl}$ containing penicillin $(10 \mathrm{U} / \mathrm{ml})$, streptomycin $(10 \mu \mathrm{g} / \mathrm{ml})$ and gentamicin $(2 \mu \mathrm{g} / \mathrm{ml})$ using a syringe with a $20 \mathrm{G} 1 "(0.9 \times 25 \mathrm{~mm})$ needle. The presence of tissue cysts in each homogenate was confirmed

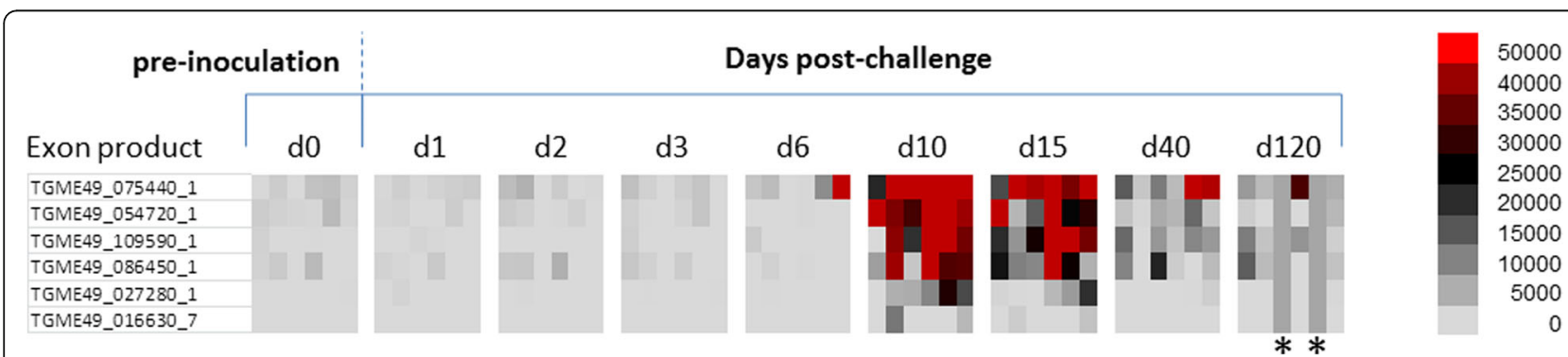

Fig. 1 Heat map representing IgM profiles at different time points in mice inoculated orally with oocysts. According to the heat map, six antigens showed significant increase at day 10 post-infection compared to day 0 pre-inoculation values. Grey columns indicated with * show the mice that did not survive until day 120 
Table 1 Antigens that showed significant lgM response at day 10 in mice infected with oocysts

\begin{tabular}{llll}
\hline Rank $^{\text {a }}$ & Gene ID_exon & Description & Benjamini-Hochberg corrected $P$-value (d0 vs d10) \\
\hline 1 & TGME49_075440_1 & Granule antigen protein GRA6 & $P<0.0001$ \\
2 & TGME49_054720_1 & Dense granule protein GRA8 & $P<0.0001$ \\
4 & TGME49_109590_1 & Rhoptry protein 1 & $P=0.0007$ \\
5 & TGME49_086450_1 & Dense granule protein 5 precursor & $P=0.0131$ \\
6 & TGME49_027280_1 & Dense granule protein GRA3 & $P=0.0077$ \\
\hline
\end{tabular}

${ }^{\mathrm{a} B a s e d}$ on average signal value, as per Figs. 1 and 2

using a phase contrast microscopy to determine if mice were infected with $T$. gondii.

\section{Protein microarray fabrication to determine IgM and IgG kinetics}

A two-step antigen discovery process was employed. In the first step, two large arrays (TG1 and TG2/3) comprising more than 2870 proteins were probed with a subset of the murine immune sera (sera from nine mice collected at day 10-15 and 40) to determine the IgG and IgM responsive predominant antigens. The first published array (TG1) comprised 1357 exon products from 615 genes [15] and the second array (TG2/3) contained 1513 exons (from 772 genes) [16]. These 2870 proteins were down-selected from $>8000$ genes (> 43,000 exons) present in the $T$. gondii genome by a bioinformatic filtering process, as previously described $[15,16]$. To isolate the exons, primers were designed from the genomic sequence of type II strain ME49 of T. gondii that was obtained from the Toxoplasma Genomics Resource (http://toxodb.org/toxo/). In the final screening, a completely new mouse array (TG4) was generated. Initially, a set of sera from day 40 for IgG and two sets of sera from day 10 and day 15 were probed against the full TG1 and TG2/3 arrays to determine the murine profile. Finally, a total of 240 exon products reactive to the murine sera were identified on the basis of this screen. These 240 plasmids were expressed and printed using the standard methods to produce a mouse-appropriate, down-selected reactive antigen array, termed here "TG4" (see Additional file 1: Table S1 for the list of 240 prioritized proteins). The final TG4 array was generated and probed with all the mouse sera samples (from day 0 to day 120) as described previously $[15,16]$. Then, the results of the array were compared to the human array profiles to determine the shared antigens both in humans and mice.

The nomenclature used in ToxoDB Toxoplasma Genomic Resource (http://toxodb.org/toxo/) is used throughout, with each gene ID appended with the exon number expressed.

\section{Statistical analysis}

The statistical analyses of arrays were handled as described previously $[15,16]$. Briefly, raw spot and local background intensities, protein annotation, and sample phenotypes are imported and merged in the $\mathrm{R}$ statistical environment, where all subsequent procedures are performed unless specified otherwise. Microarray spot intensities are quantified using ScanArrayExpress software (Perkin Elmer, USA) utilizing automatic local background subtraction for each

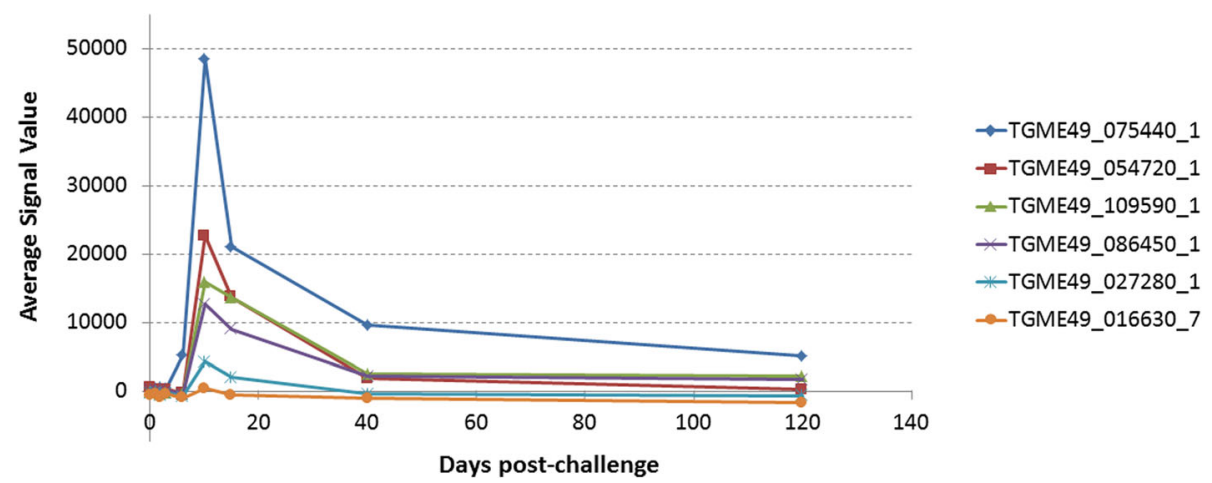

Fig. 2 Line chart of IgM kinetics at different time points in mice inoculated orally with oocysts. Line chart of six antigens, shown in Table 1 overlaid with Benjamini-Hochberg-corrected $P$-values comparing data for day 10 post-infection with pre-inoculation values. Signal values are average of adjusted array signals (raw in vitro transcription/translation [IVTT] signals subtracted of median of sample-specific control IVTT spots) \pm SD 
spot. The generated signal intensity values are considered raw values. Next, all raw values are transformed using the base 2 logarithm $\left(\log _{2}\right)$. Antibody magnitude is defined as signal intensity of reactive antigens with respect to NoDNA probes. To calculate the magnitude of antibody responses, the median normalized signal intensity ( $\log _{2}$ scale) of the NoDNA probes per individual is subtracted from target probe normalized signal intensities for each individual.

All statistical analyses for microarray data were performed using the $\mathrm{R}$ statistical environment software (http://www.r-project.org). A Bayes regularized t-test is adapted from Cyber- $\mathrm{T}$ for protein arrays. To account for multiple testing conditions, the Benjamini \& Hochberg [20] (BH) method is used to control the false discovery rate. After Benjamini-Hochberg correction, $P$-values smaller than 0.05 are considered significant, and the corresponding protein is considered differentially reactive.

\section{Results}

Serum samples were collected from two groups of mice, infected orally with viable oocysts and tissue cysts, before infection (Day 0) as well as 1, 2, 3, 6, 10, 15, 40 and
120 days after infection. Next, IgM and IgG antibody kinetics of these sera were analyzed by protein microarrays comprising 240 prioritized proteins.

\section{IgM kinetics of mice infected with oocysts}

During the screening in the group of mice infected with viable oocysts, the IgM response reached maximal intensity and breadth around day 10 , as seen in the heat map in Fig. 1. Responses against 6 antigens increased significantly at day 10 compared to day $0(P$-values are listed in Table 1$)$. Of the 5 antigens listed in Table 1, one of them is rhoptry protein and four are dense granule proteins which were all excreted secreted antigens (ESA) (Table 1). The IgM response decreased steadily after day 10 (Fig. 2).

\section{IgG kinetics of mice infected with oocysts}

During the screening, IgG response against 40 antigens reached maximal intensity and breadth around day 40 as seen in the heat map in Fig. 3. IgG responses against 40 antigens increased significantly at day 40 compared to day 0 ( $P$-values are listed in

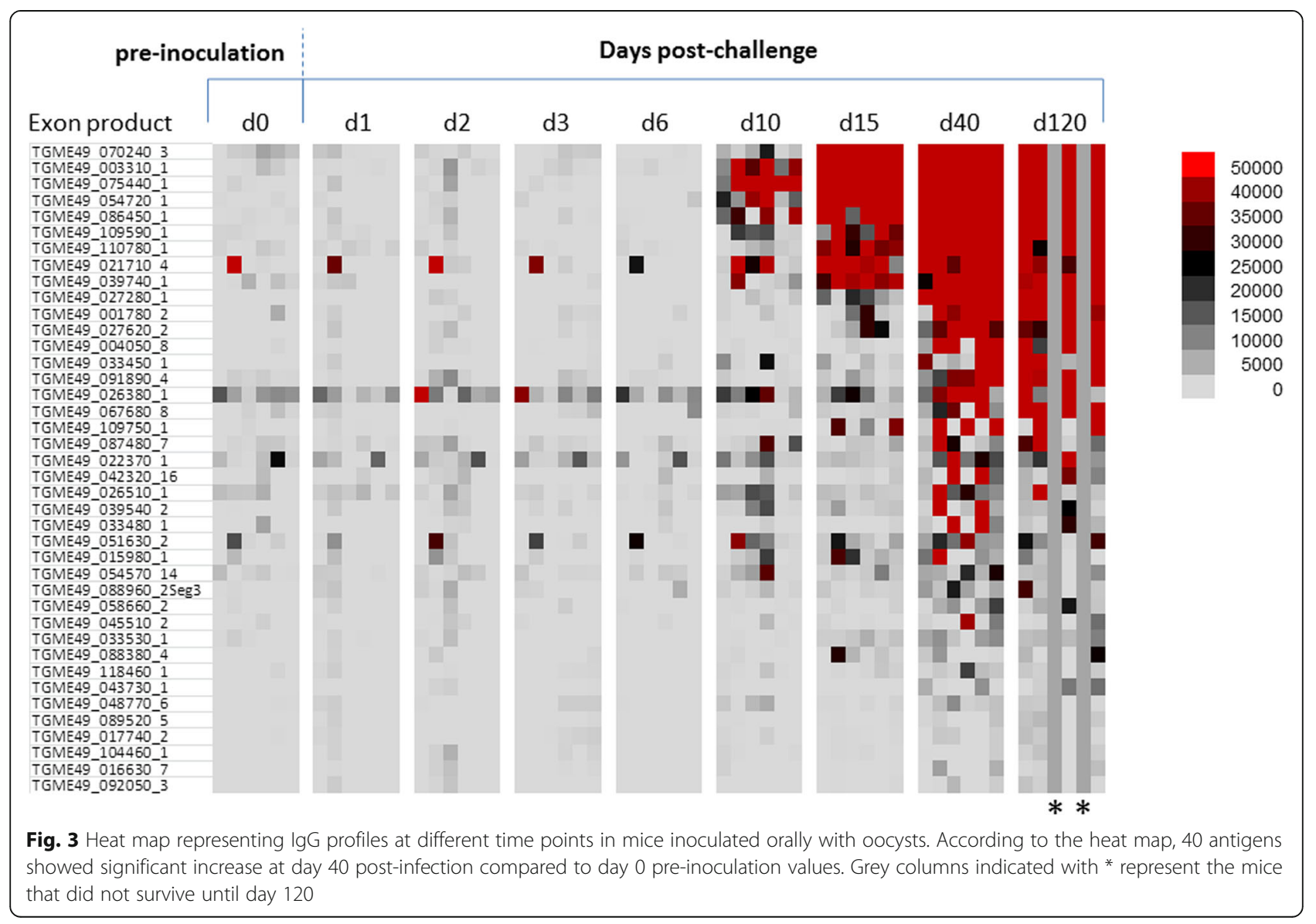


Table 2 Antigens that showed significant lgG response at day 40 in mice infected with oocysts

\begin{tabular}{|c|c|c|c|}
\hline Rank $^{a}$ & Gene ID_exon & Description & $\begin{array}{l}\text { Benjamini-Hochberg corrected } \\
P \text {-value (d0 vs d40) }\end{array}$ \\
\hline 1 & TGME49_070240_3 & Unspecified product (MAG1) & $P<0.0001$ \\
\hline 2 & TGME49_003310_1 & Dense granule protein GRA7 & $P<0.0001$ \\
\hline 3 & TGME49_075440_1 & Granule antigen protein GRA6 & $P<0.0001$ \\
\hline 4 & TGME49_054720_1 & Dense granule protein GRA8 & $P<0.0001$ \\
\hline 5 & TGME49_086450_1 & Dense granule protein 5 precursor & $P<0.0001$ \\
\hline 6 & TGME49_109590_1 & Rhoptry protein 1 & $P<0.0001$ \\
\hline 7 & TGME49_110780_1 & Dense granule protein GRA4 & $P<0.0001$ \\
\hline 8 & TGME49_021710_4 & TBC domain-containing protein & $P=0.0014$ \\
\hline 9 & TGME49_039740_1 & Dense granule protein GRA14 & $P<0.0001$ \\
\hline 10 & TGME49_027280_1 & Dense granule protein GRA3 & $P<0.0001$ \\
\hline 11 & TGME49_001780_2 & Microneme protein MIC2 & $P=0.0003$ \\
\hline 12 & TGME49_027620_2 & Dense granule protein GRA2 & $P<0.0001$ \\
\hline 13 & TGME49_004050_8 & Subtilisin SUB1 & $P=0.0007$ \\
\hline 14 & TGME49_033450_1 & SAG-related sequence SRS29A & $P=0.0151$ \\
\hline 15 & TGME49_091890_4 & Microneme protein MIC1 & $P=0.0003$ \\
\hline 16 & TGME49_026380_1 & Hypothetical protein & $P=0.0429$ \\
\hline 17 & TGME49_067680_8 & Microneme protein MIC12 & $P=0.0151$ \\
\hline 18 & TGME49_109750_1 & Succinate-Coenzyme A ligase, beta subunit & $P=0.0275$ \\
\hline 19 & TGME49_087480_7 & Hypothetical protein & $P=0.0483$ \\
\hline 20 & TGME49_022370_1 & SAG-related sequence SRS13 & $P=0.0445$ \\
\hline 21 & TGME49_042320_16 & B-box zinc finger domain-containing protein & $P=0.0190$ \\
\hline 22 & TGME49_026510_1 & Sec23/Sec24 trunk domain-containing protein & $P=0.0359$ \\
\hline 23 & TGME49_039540_2 & LEM3 (ligand-effect modulator 3) family & $P=0.0280$ \\
\hline 24 & TGME49_033480_1 & SAG-related sequence SRS29C & $P=0.0358$ \\
\hline 25 & TGME49_051630_2 & Slc30a2 protein & $P=0.0361$ \\
\hline 26 & TGME49_015980_1 & Hypothetical protein & $P=0.0358$ \\
\hline 27 & TGME49_054570_14 & Hypothetical protein & $P=0.0483$ \\
\hline 28 & TGME49_088960_2Seg3 & Hypothetical protein & $P=0.0358$ \\
\hline 29 & TGME49_058660_2 & Rhoptry protein ROP6 & $P=0.0358$ \\
\hline 30 & TGME49_045510_2 & Phospholipid-translocating P-type ATPase & $P=0.0483$ \\
\hline 31 & TGME49_033530_1 & Hypothetical protein & $P=0.0364$ \\
\hline 32 & TGME49_088380_4 & Heat shock protein HSP90 & $P=0.0430$ \\
\hline 33 & TGME49_118460_1 & P-type ATPase & $P=0.0430$ \\
\hline 34 & TGME49_043730_1 & Rhoptry protein ROP9 & $P=0.0364$ \\
\hline 35 & TGME49_048770_6 & Hypothetical protein & $P=0.0430$ \\
\hline 36 & TGME49_089520_5 & Hypothetical protein & $P=0.0498$ \\
\hline 37 & TGME49_017740_2 & 3-ketoacyl-(acyl-carrier-protein) reductase & $P=0.0483$ \\
\hline 38 & TGME49_104460_1 & Zinc finger, C3HC4 type (RING finger) domain-containing protein & $P=0.0483$ \\
\hline 39 & TGME49_016630_7 & Trigger factor protein, putative & $P=0.0498$ \\
\hline 40 & TGME49_092050_3 & Calcium dependent protein kinase CDPK8 & $P=0.0483$ \\
\hline
\end{tabular}

${ }^{\mathrm{a}}$ Based on average signal value, as per Figs. 3 and 4 


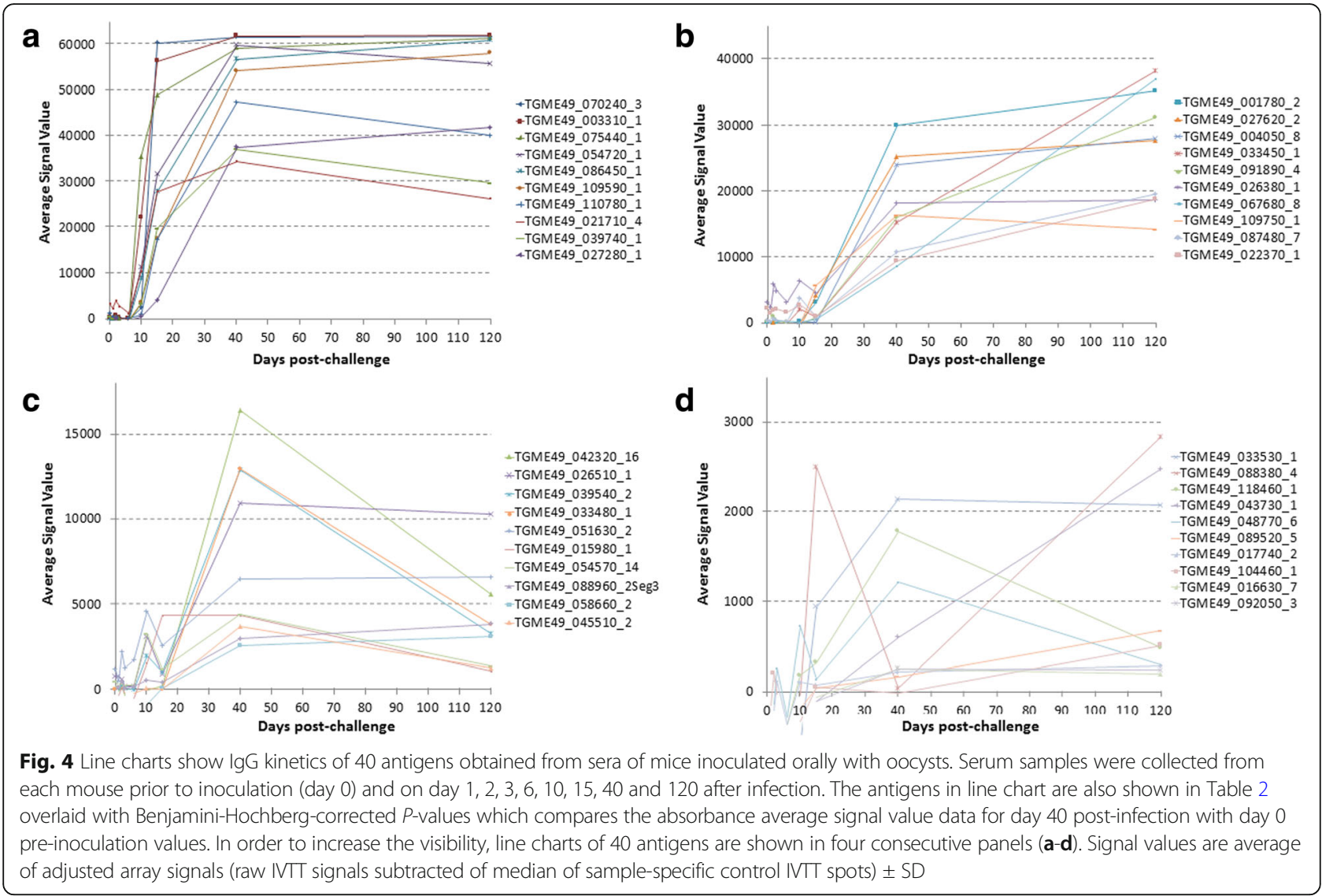

Table 2). The IgG response mostly first peaked at day 10 or afterwards (Fig. 4a-d). Among the first five highest signal giving proteins, four of them are dense granule proteins which were ESA (Table 2).

\section{IgM kinetics of mice infected with tissue cysts}

During the screening in the group of mice infected with viable tissue cysts, the IgM response reached maximal intensity and breadth around day 10 , as seen in the heat map in Fig. 5. IgM responses against 6 antigens increased significantly at day 10 compared to day 0 $(P$-values are listed in Table 3). Of the 5 antigens listed in Table 1, one of them is rhoptry protein and two of them are dense granule proteins which all ESA. The IgM response decreased steadily after day 15 (Fig. 6).

\section{IgG kinetics of mice infected with tissue cysts}

During the screening, IgG response against 40 antigens reached maximal intensity and breadth around day 40 as seen in the heat map in Fig. 7. IgG responses against 40 antigens increased significantly at day 40 compared to day compared to day 0 ( $P$-values are listed in Table 4$)$. The IgG response mostly gave first peaks at day 10 or afterwards (Fig. 8a-d). Among the first five highest signal giving proteins, one of them is rhoptry protein and three of them are dense granule proteins which were ESA (Table 4).

\section{Discussion}

The realization of the importance of antigen discovery to develop diagnostic assays or a protective vaccine has

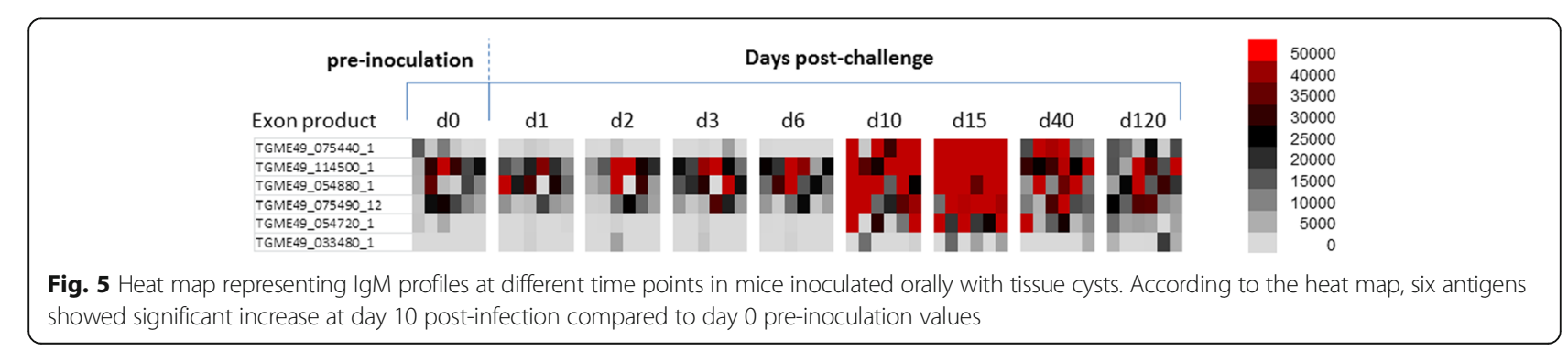


Table 3 Antigens that showed significant IgM response at day 10 in mice infected with tissue cysts

\begin{tabular}{llll}
\hline Rank $^{a}$ & Gene ID_exon & Description & $\begin{array}{l}\text { Benjamini-Hochberg corrected } \\
P \text {-value (d0 vs d10) }\end{array}$ \\
\hline 1 & TGME49_075440_1 & Granule antigen protein GRA6 & $P=0.0493$ \\
2 & TGME49_114500_1 & Subtilisin SUB2 & $P=0.0497$ \\
3 & TGME49_054880_1 & Alpha-galactosidase & $P=0.0493$ \\
4 & TGME49_075490_12 & Hypothetical protein & $P=0.0493$ \\
6 & TGME49_054720_1 & Dense granule protein GRA8 & $P=0.0493$ \\
\hline
\end{tabular}

${ }^{\mathrm{a}}$ Based on average signal value, as per Figs. 5 and 6

increased in the last decade. During the development of a diagnostic serological assay to detect acute toxoplasmosis, antigens expressed during the acute toxoplasmosis can be much preferred. Plenty of antigens such as SAG1, SAG2, SAG2A, ROP1, ROP2, GRA1, GRA2, GRA3, GRA4, GRA5, GRA6, GRA7, GRA8, MIC1, MIC2, MIC3, MIC4, M2AP, AMA1, HSP20, BAG1 (HSP30), MAG1, NTPase, P25, P35, P68 and multi-epitope peptide containing epitopes of SAG1, SAG2 and SAG3 have been tested by ELISA methods with well categorized sera obtained from human or animal models so far to diagnose acute toxoplasmosis [13].

In the case of development of a protective vaccine against toxoplasmosis, vaccine formulations should contain antigens from each stage of the parasite to sequentially block the parasite during the invasion of host cells. More than 60 proteins have been tested as vaccine candidate antigens up to date [12], but none of them conferred the desired efficacy to be able to proceed to clinical trial. Randomly chosen vaccine candidate antigens, such as structural proteins or metabolic enzymes, have delayed the progress in vaccine development pipeline for $T$. gondii.

In the life-cycle of $T$. gondii, tissue cysts (containing bradyzoites) and oocysts (containing sporozoites) are the main forms of the parasite that transmit the disease in nature. As they enter the host cell, bradyzoites and sporozoites both convert to motile tachyzoites which invade the tissues. Just as the immune response starts to respond to the parasite, tachyzoites change into slowly dividing bradyzoites and remain latent in a tissue cyst [21]. Thus, a successful vaccine against $T$. gondii is likely to contain antigens from all forms of the parasite and selected using a rational approach.

To address these issues, we screened the serum samples from mice orally infected with tissue cysts and oocysts. Sera were collected prior to administration (Day $0)$ as well as 1, 2, 3, 6, 10, 15, 40 and 120 days after infection from these mice to characterize the immune response during the first dates and thereafter. By screening these mice sera, we identified the antigens that give prominent immune response during infection initiated with oocysts or tissue cysts. In addition, antibody kinetics of each antigen was displayed.

In the mice infected with oocysts, 6 IgM and 40 IgG immune-reactive antigens were discovered that showed significant increment in response compared to baseline (Figs. 1, 2, 3 and 4). In the group infected with tissue cysts, 6 IgM and 40 IgG immune-reactive antigens were identified (Figs. 5, 6, 7 and 8). Oocyst and tissue cyst fed mice showed significant IgM response at day 10 . Thereafter, a decline was observed in IgM response after day 10 in oocyst-infected mice but in the group of mice

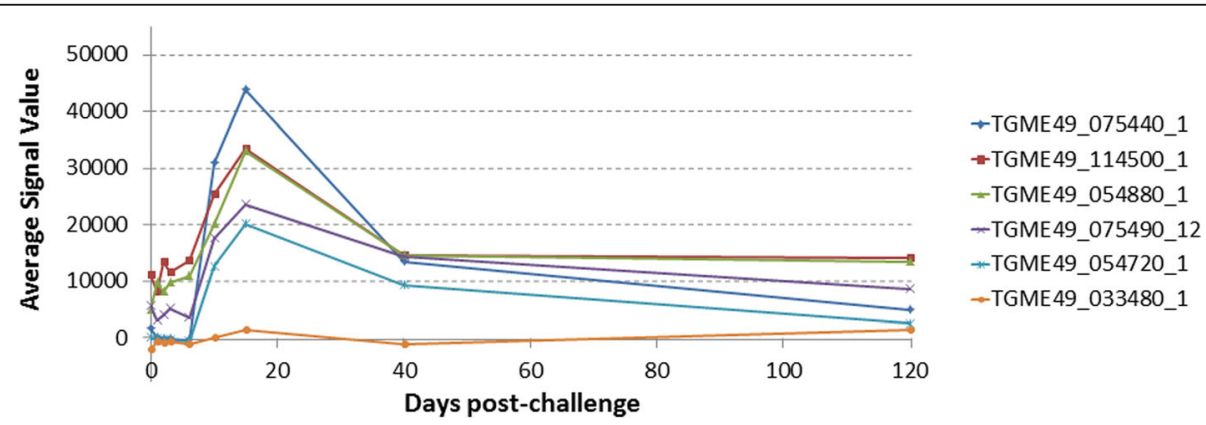

Fig. 6 Line chart represent lgM kinetics specific for six antigens probed with sera collected from mice at different time points inoculated orally with tissue cysts. These six antigens are also shown in Table 3 overlaid with Benjamini-Hochberg-corrected $P$-values comparing the absorbance average signal value data for day 10 post-infection with day 0 pre-inoculation values. Signal values are average of adjusted array signals (raw IVTT signals subtracted of median of sample-specific control IVTT spots) \pm SD 


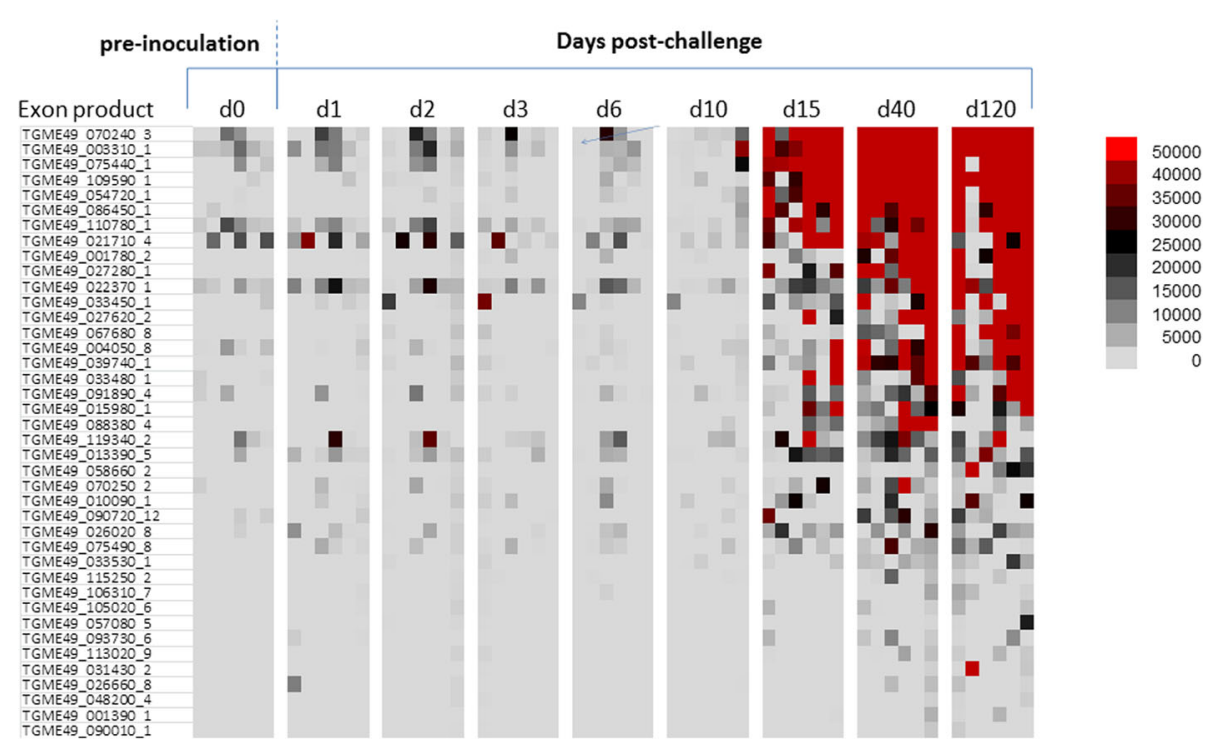

Fig. 7 Heat map representing lgG profiles at different time points in mice inoculated orally with tissue cysts. According to the heat map, 40 antigens showed significant increase at day 40 post-infection compared to day 0 pre-inoculation values

infected with tissue cyst, the increment in IgM response continued until day15 and then declined. This is consistent with tissue cyst bradyzoites requiring more time to invade the host cells. The IgG response first appeared mostly around at day 15 , peaked at day 40 and remained elevated or increased through day 120 . Overall, there are 12 antigens discovered during IgM screening and 80 proteins during IgG screening.

If we look from the point of view of selecting an antigen(s) to develop a serological diagnostic assays or vaccine, we have to focus on the antigens that play significant roles in pathogenesis. During the invasion, MIC proteins are secreted from small apical organelles called microneme. MICs are adhesin proteins that help the parasite to attach to the host plasma membrane. ROP proteins are secreted from unique elongated organelles called rhoptry. ROPs are secreted from the apical end into the cytoplasm of host cells and help the formation of parasitophorous vacuole (PV) derived from host cell membrane. Once the parasite gets inside PV, GRAs which are dense granule proteins are released into the PV that modifies the vacuole membrane [22]. Thus, antigens to be used in diagnostic serological assays or vaccine formulations are needed to: (i) actively induce strong immune response at the very beginning of the infection (i.e. strong IgM response during the first 10-15 days of infection); (ii) induce long-lasting immunity (i.e. strong IgG response until day 120); (iii) be antigenic in both forms of the parasite because transmission can occur through oocysts or tissue cysts.

From the accumulated screening data, two antigens GRA6 (TGME49_075440) and GRA8 (TGME49_054
720) have all of the above-mentioned properties. In addition, GRA3 (TGME49_027280), GRA5 (TGME4 9_086450), ROP1 (TGME49_109590) and SAG-related sequence SRS29C (TGME49_033480) have similar properties excluding antigenicity in IgM response in oocyst infected mice. Besides, there are 11 antigens that induce long-lasting IgG response in both oocyst and tissue cyst infected mice which are the cyst matrix protein MAG1 (TGME49_070240); dense granule proteins GRA2 (TGME49_027620), GRA4 (TGME49_110780), GRA7 (TGME49_003310) and GRA14 (TGME49_039740); microneme proteins MIC1 (TGME49_091890), MIC2 (TGME49_001780) and MIC12 (TGME49_067680); surface proteins SAG-related sequence SRS13 (TGME49 022370) and SRS29A (TGME49_033450); rhoptry protein ROP6 (TGME49_058660).

When we match the human screening data from our previous studies $[15,16]$ with these mouse response antigens, 16 of these antigens showed a strong response in human sera samples except SAG-related sequence SRS29C (TGME49_033480).

Two studies about transcriptomic and proteomic analyses of $T$. gondii confirmed that GRA2, GRA3, GRA4, GRA5, GRA6, GRA7, GRA8, GRA14, MIC1, MIC2, MIC12, ROP1, ROP6 and SRS29C, expression levels are elevated in sporozoites at days 4 and 10 of infection relative to day 0 of infection, suggesting an important role in host cell invasion [23, 24]. Among the above-mentioned antigens, ROP1, GRA2, GRA4, GRA5, GRA6, GRA7, GRA14, MIC1, MIC2 and MAG1 have been used as vaccine candidate antigens in previous studies and showed strong immunogenicity [12, 25-44]. GRA3 and GRA8 
Table 4 Antigens that showed significant lgG response at day 40 in mice infected with tissue cysts

\begin{tabular}{|c|c|c|c|}
\hline Rank $^{a}$ & Gene ID_exon & Description & $\begin{array}{l}\text { Benjamini-Hochberg corrected } \\
P \text {-value (d0 vs d40) }\end{array}$ \\
\hline 1 & TGME49_070240_3 & Unspecified product (MAG1) & $P=0.0006$ \\
\hline 2 & TGME49_003310_1 & Dense granule protein GRA7 & $P=0.0017$ \\
\hline 3 & TGME49_075440_1 & Granule antigen protein GRA6 & $P=0.0006$ \\
\hline 4 & TGME49_109590_1 & Rhoptry protein 1 & $P=0.0006$ \\
\hline 5 & TGME49_054720_1 & Dense granule protein GRA8 & $P=0.0006$ \\
\hline 6 & TGME49_086450_1 & Dense granule protein 5 precursor & $P=0.0006$ \\
\hline 7 & TGME49_110780_1 & Dense granule protein GRA4 & $P=0.0092$ \\
\hline 8 & TGME49_021710_4 & TBC domain-containing protein & $P=0.0180$ \\
\hline 9 & TGME49_001780_2 & Microneme protein MIC2 & $P=0.0037$ \\
\hline 10 & TGME49_027280_1 & Dense granule protein GRA3 & $P=0.0006$ \\
\hline 11 & TGME49_022370_1 & SAG-related sequence SRS13 & $P=0.0187$ \\
\hline 12 & TGME49_033450_1 & SAG-related sequence SRS29A & $P=0.0475$ \\
\hline 13 & TGME49_027620_2 & Dense granule protein GRA2 & $P=0.0092$ \\
\hline 14 & TGME49_067680_8 & Microneme protein $\mathrm{MIC} 12$ & $P=0.0187$ \\
\hline 15 & TGME49_004050_8 & Subtilisin SUB1 & $P=0.0317$ \\
\hline 16 & TGME49_039740_1 & Dense granule protein GRA14 & $P=0.0006$ \\
\hline 17 & TGME49_033480_1 & SAG-related sequence SRS29C & $P=0.0477$ \\
\hline 18 & TGME49_091890_4 & Microneme protein MIC1 & $P=0.0354$ \\
\hline 19 & TGME49_015980_1 & Hypothetical protein & $P=0.0010$ \\
\hline 20 & TGME49_088380_4 & Heat shock protein HSP90 & $P=0.0012$ \\
\hline 21 & TGME49_119340_2 & Hypothetical protein & $P=0.0280$ \\
\hline 22 & TGME49_013390_5 & Plectin, putative & $P=0.0370$ \\
\hline 23 & TGME49_058660_2 & Rhoptry protein ROP6 & $P=0.0355$ \\
\hline 24 & TGME49_070250_2 & Dense granule protein GRA1 & $P=0.0388$ \\
\hline 25 & TGME49_010090_1 & Protein kinase domain-containing protein & $P=0.0354$ \\
\hline 26 & TGME49_090720_12 & Vacuolar proton translocating ATPase subunit, putative & $P=0.0297$ \\
\hline 27 & TGME49_026020_8 & Transporter, major facilitator family protein & $P=0.0485$ \\
\hline 28 & TGME49_075490_8 & Hypothetical protein & $P=0.0388$ \\
\hline 29 & TGME49_033530_1 & Hypothetical protein & $P=0.0099$ \\
\hline 30 & TGME49_115250_2 & GAMM1 protein, putative & $P=0.0485$ \\
\hline 31 & TGME49_106310_7 & RecF/RecN/SMC N terminal domain-containing protein & $P=0.0187$ \\
\hline 32 & TGME49_105020_6 & Hypothetical protein & $P=0.0387$ \\
\hline 33 & TGME49_057080_5 & 3'5'-cyclic nucleotide phosphodiesterase domain-containing protein & $P=0.0408$ \\
\hline 34 & TGME49_093730_6 & DHHC zinc finger domain-containing protein & $P=0.0108$ \\
\hline 35 & TGME49_113020_9 & STAS domain-containing protein & $P=0.0134$ \\
\hline 36 & TGME49_031430_2 & Oligosaccharyl transferase stt3 protein, putative & $P=0.0365$ \\
\hline 37 & TGME49_026660_8 & Hypothetical protein & $P=0.0187$ \\
\hline 38 & TGME49_048200_4 & Ribosomal RNA- dimethyltransferase, putative & $P=0.0488$ \\
\hline 39 & TGME49_001390_1 & Hypothetical protein & $P=0.0180$ \\
\hline 40 & TGME49_090010_1 & Hypothetical protein & $P=0.0485$ \\
\hline
\end{tabular}

${ }^{a}$ Based on average signal value, as per Figs. 7 and 8 


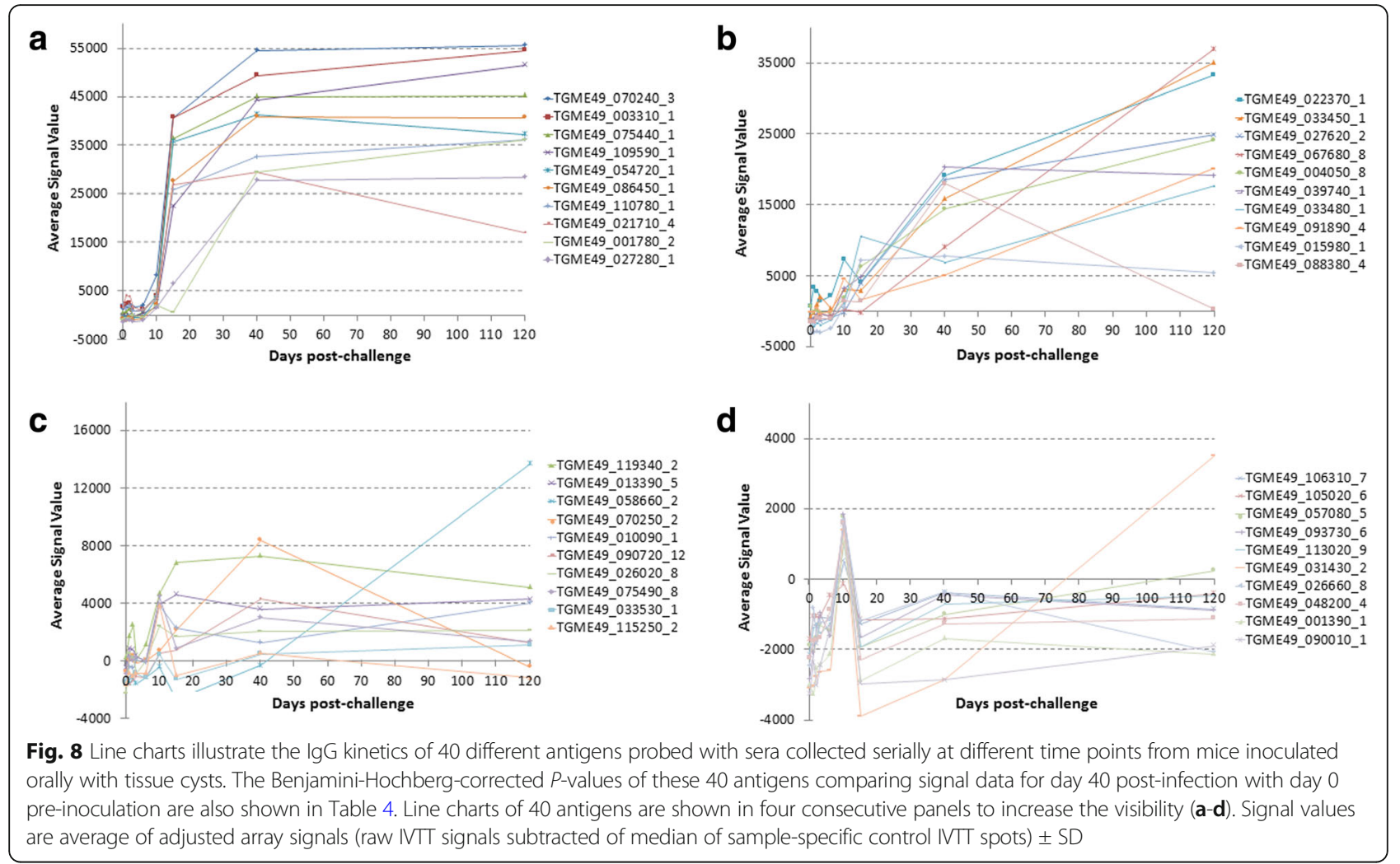

have been evaluated with ELISA and showed some immunity with human samples [45-48]. SRS29C have been identified as an important negative regulator of acute virulence in murine models [49].

\section{Conclusion}

Our approach has revealed that ROP6, MIC12, SRS29A and SRS13 have shown strong immunogenicity and at the same time not tested in development of a diagnostic assay or a vaccine model yet. In addition, it seems that GRA3 and GRA 8 can be a good vaccine candidate that has not been tested in an animal model yet. The protective efficiency and immunity of SRS29C can be analyzed in a comprehensive vaccine study. In development of a diagnostic assay to detect acute toxoplasmosis, the evaluation of ROP6, MIC12, SRS29A and SRS13 IgM/IgG kinetics with well categorized human sera can give some clue about acute toxoplasmosis. Multivalent vaccine formulations or ELISAs using several antigens of $T$. gondii have been found more successful in previous studies in terms of protection against toxoplasmosis and diagnosing acute toxoplasmosis. Thus, blending the novel antigens discovered in this study with previously immunogenic antigens in diagnostic assays or vaccine formulations may give better results. We must also bear in mind that the protection against toxoplasmosis is conferred mainly by cellular immune response and through humoral immune response [22]. Screening of cellular immunity of humans and animals against toxoplasmosis will definitely give more clues about protective antigens but a robust high-throughput wet lab approach does not exist currently. On the other hand, the antigens discovered in this study are reactive with IgM and IgG antibodies and showed strong immunogenicity and could give researchers some clue to develop a vaccine against toxoplasmosis or diagnostic serological kit.

\section{Additional file}

Additional file 1: Table S1. 240 exon products reactive with murine sera comprising the mouse array TG4. (XLSX $20 \mathrm{~kb}$ )

\section{Abbreviations}

ROP: rhoptry protein; GRA: dense granule protein; MIC: microneme protein; MAG: cyst matrix protein; SRS: SAG-related sequence; AVMA: American Veterinary Medical Association; FEDIAF: The European Pet Food Industry Federation; TG1, TG2/3, TG4: microarrays developed to detect T. gondii antigens; ToxoDB: Toxoplasma Genomic Resource; TGME49: T. gondii ME49 strain; IVTT: in vitro transcription/translation; SD: Standard deviation

\section{Acknowledgements}

The authors would like to acknowledge Toxoplasma Biological Resource Center (BRC)/Centre National de Référence (CNR) Toxoplasmose for providing $T$. gondii PRU strain. 


\section{Funding}

This study was supported in part by The Scientific and Technological Research Council of Turkey grant 110 S200 to AYG and in part by National Institute of Allergy and Infectious Diseases grant Al058365 to DHD. The funders had no role in study design, data collection and analysis, decision to publish, or preparation of the manuscript.

\section{Availability of data and materials}

The datasets generated and analyzed during the current study are available in the Figshare repository, https://figshare.com/s/2ecdcd4a875cffbc13b3.

\section{Authors' contributions}

$M D, L L, A J, H C, S G I, P L P, A D D, D H D$ and AYG conceived the study. AYG and DHD obtained funding. MD, DHD, LL and PLP analyzed the data. DHD, MD, PLP and AYG prepared the manuscript. All authors read and approved the final manuscript.

\section{Ethics approval and consent to participate}

All in vivo studies were performed according to Guide for the Care and Use of Laboratory Animals approved by the Institutional Animal Care and Use Committee (IACUC) of Ege University (Turkey) for animal ethical norms (Permit number: 2009-155).

\section{Competing interests}

$M D, A Y G, D H D$ and PLF are inventors on patent applications pertaining to this work. DHD and PLF own stock in a company (Antigen Discovery Inc.) that has licensed the technology. The terms of this arrangement have been approved by the UCI Conflict of Interest Committee. LL, AJ, HC, SGI, ADD declare that they have no competing interests.

\section{Publisher's Note}

Springer Nature remains neutral with regard to jurisdictional claims in published maps and institutional affiliations.

\section{Author details}

'Department of Parasitology, Vaccine Research and Development Laboratory, Ege University Faculty of Medicine, Bornova/Izmir, Turkey. ${ }^{2}$ Department of Medicine, Division of Infectious Diseases, University of California Irvine, Irvine, California, USA. ${ }^{3}$ Department of Molecular Biology, Ege University Faculty of Sciences, Bornova/Izmir, Turkey. ${ }^{4}$ Department of Bioengineering, Ege University Faculty of Engineering, Bornova/Izmir, Turkey.

Received: 4 March 2018 Accepted: 4 June 2018

Published online: 04 July 2018

\section{References}

1. Montoya JG, Liesenfeld O. Toxoplasmosis. Lancet. 2004;363:1965-76.

2. Torrey EF, Bartko JJ, Yolken RH. Toxoplasma gondii and other risk factors for schizophrenia: an update. Schizophr Bull. 2012;38:642-7.

3. Holland GN. Ocular toxoplasmosis: a global reassessment. Part l: epidemiology and course of disease. Am J Ophthalmol. 2003;136:973-88.

4. Jones JL, Kruszon-Moran D, Sanders-Lewis K, Wilson M. Toxoplasma gondii infection in the United States, 1999-2004, decline from the prior decade. Am J Trop Med Hyg. 2007;77:405-10.

5. NIAID (National Institute of Allergy and Infectious Diseases) Category A, B and C Priority Pathogens. https://www.niaid.nih.gov/research/emerginginfectious-diseases-pathogens. Accessed date: March 25 $5^{\text {th }}, 2018$

6. Bowie WR, King AS, Werker DH, Isaac-Renton JL, Bell A, Eng SB, et al. Outbreak of toxoplasmosis associated with municipal drinking water. The BC Toxoplasma Investigation Team. Lancet. 1997;350:173-7.

7. Bahia-Oliveira LM, Jones JL, Azevedo-Silva J, Alves CC, Oréfice F, Addiss DG Highly endemic, waterborne toxoplasmosis in north Rio de Janeiro State, Brazil. Emerg Infect Dis. 2003;9:55-62.

8. Palanisamy M, Madhavan B, Balasundaram MB, Andavar R, Venkatapathy N Outbreak of ocular toxoplasmosis in Coimbatore, India. Indian J Ophthalmol. 2006:54:129-31.

9. Doganci L, Tanyuksel M, Araz ER, Besirbellioglu BA, Erdem U, Ozoguz CA, et al. A probable outbreak of toxoplasmosis among boarding school students in Turkey. Clin Microbiol Infect. 2006;12:672-4.
10. AVMA (American Veterinary Medical Association) U.S. Pet Ownership Statistics. 2012. https://www.avma.org/KB/Resources/Statistics/Pages/ Market-research-statistics-US-pet-ownership.aspx. Accessed 25 Mar 2018.

11. FEDIAF (The European Pet Food Industry Federation) Facts and Figures. 2016. http://www.fediaf.org/who-we-are/european-statistics.html. Accessed 7 June 2018.

12. Gedik Y, Gülçe İ S, Can H, Değirmenci Döşkaya A, Deliloğlu Gürhan Sİ, Gürüz $Y$, et al. Immunogenic multistage recombinant protein vaccine confers partial protection against experimental toxoplasmosis mimicking natural infection in murine model. Trials Vaccinol. 2016;5:15-23.

13. Döşkaya M, Caner A, Can H, Gülçe Iz S, Gedik Y, Döşkaya AD, et al. Diagnostic value of a Rec-ELISA using Toxoplasma gondii recombinant SporoSAG, BAG1, and GRA1 proteins in murine models infected orally with tissue cysts and oocysts. PLoS One. 2014;9:e108329.

14. Davies DH, Liang X, Hernandez JE, Randall A, Hirst S, Mu Y, et al. Profiling the humoral immune response to infection by using proteome microarrays: high-throughput vaccine and diagnostic antigen discovery. Proc Natl Acad Sci USA. 2005;102:547-52.

15. Liang L, Döșkaya M, Juarez S, Caner A, Jasinskas A, Tan X, et al. Identification of potential serodiagnostic and subunit vaccine antigens by antibody profiling of toxoplasmosis cases in Turkey. Mol Cell Proteomics. 2011;10: M110.006916.

16. Felgner J, Juarez S, Hung C, Liang LI, Jain A, Döşkaya M, et al. Identification of Toxoplasma gondii antigens associated with different types of infection by serum antibody profiling. Parasitology. 2015;142:827-38.

17. Dubey JP, Beattie CP. Toxoplasmosis of animals and humans. New York: CRC Press; 1988.

18. Dumètre A, Dardé ML. Purification of Toxoplasma gondii oocysts by cesium chloride gradient. J Microbiol Methods. 2004;56:427-30.

19. Staggs SE, See MJ, Dubey JP, Villegas EN. Obtaining highly purified Toxoplasma gondii oocysts by a discontinuous cesium chloride gradient. J Vis Exp. 2009:3:1420.

20. Benjamini $Y$, Hochberg $Y$. Controlling the false discovery rate: a practical and powerful approach to multiple testing. J R Stat Soc B. 1995:57:289-300.

21. Kim K. Role of proteases in host cell invasion by Toxoplasma gondii and other Apicomplexa. Acta Trop. 2004:91:69-81.

22. Weiss LM, Kim K. Toxoplasma gondii, the model apicomplexan: perspectives and methods. London, Great Britain: Elsevier Ltd; 2007.

23. Fritz HM, Bowyer PW, Bogyo M, Conrad PA, Boothroyd JC. Proteomic analysis of fractionated Toxoplasma oocysts reveals clues to their environmental resistance. PLoS One. 2012;7:e29955.

24. Fritz HM, Buchholz KR, Chen X, Durbin-Johnson B, Rocke DM, Conrad PA, et al. Transcriptomic analysis of Toxoplasma development reveals many novel functions and structures specific to sporozoites and oocysts. PLoS One. 2012;7:e29998.

25. Sonaimuthu $P$, Ching XT, Fong MY, Kalyanasundaram R, Lau YL. Induction of protective immunity against toxoplasmosis in BALB/C mice vaccinated with Toxoplasma gondii Rhoptry-1. Front Microbiol. 2016;7:808.

26. Quan JH, Chu JQ, Ismail HA, Zhou W, Jo EK, Cha GH, et al. Induction of protective immune responses by a multiantigenic DNA vaccine encoding GRA7 and ROP1 of Toxoplasma gondii. Clin Vaccine Immunol. 2012:19: 666-74

27. Desolme B, Mévélec MN, Buzoni-Gatel D, Bout D. Induction of protective immunity against toxoplasmosis in mice by DNA immunization with a plasmid encoding Toxoplasma gondii GRA4 gene. Vaccine. 2000;18:2512-21.

28. Martin V, Supanitsky A, Echeverria PC, Litwin S, Tanos T, De Roodt AR, et al. Recombinant GRA4 or ROP2 protein combined with alum or the gra4 gene provides partial protection in chronic murine models of toxoplasmosis. Clin Diagn Lab Immunol. 2004;11:704-10.

29. Sánchez VR, Pitkowski MN, Fernández Cuppari AV, Rodríguez FM, Fenoy IM, Frank FM, et al. Combination of CpG-oligodeoxynucleotides with recombinant ROP2 or GRA4 proteins induces protective immunity against Toxoplasma gondii infection. Exp Parasitol. 2011;128:448-53.

30. Meng M, Zhou A, Lu G, Wang L, Zhao G, Han Y, et al. DNA prime and peptide boost immunization protocol encoding the Toxoplasma gondii GRA4 induces strong protective immunity in BALB/c mice. BMC Infect Dis. 2013;13:494

31. Igarashi M, Kano F, Tamekuni K, Machado RZ, Navarro IT, Vidotto O, et al. Toxoplasma gondii: evaluation of an intranasal vaccine using recombinant proteins against brain cyst formation in BALB/C mice. Exp Parasitol. 2008; 118:386-92. 
32. Feliu V, Vasseur V, Grover HS, Chu HH, Brown MJ, Wang J, et al. Location of the CD8 T cell epitope within the antigenic precursor determines immunogenicity and protection against the Toxoplasma gondii parasite. PLoS Pathog. 2013;9:e1003449.

33. Sun XM, Zou J, A A ES, Yan WC, Liu XY, Suo X, et al. DNA vaccination with a gene encoding Toxoplasma gondii GRA6 induces partial protection against toxoplasmosis in BALB/C mice. Parasit Vectors. 2011;4:213.

34. Golkar M, Shokrgozar MA, Rafati S, Musset K, Assmar M, Sadaie R, et al. Evaluation of protective effect of recombinant dense granule antigens GRA2 and GRA6 formulated in monophosphoryl lipid A (MPL) adjuvant against Toxoplasma chronic infection in mice. Vaccine. 2007;25:4301-11.

35. Hiszczyńska-Sawicka E, Olędzka G, Holec-Gąsior L, Li H, Xu JB, Sedcole R, et al. Evaluation of immune responses in sheep induced by DNA immunization with genes encoding GRA1, GRA4, GRA6 and GRA7 antigens of Toxoplasma gondii. Vet Parasitol. 2011:177:281-9.

36. Jongert E, de Craeye S, Dewit J, Huygen K. GRA7 provides protective immunity in cocktail DNA vaccines against Toxoplasma gondii. Parasite Immunol. 2007;29:445-53.

37. Jongert E, Melkebeek V, De Craeye S, Dewit J, Verhelst D, Cox E. An enhanced GRA1-GRA7 cocktail DNA vaccine primes anti-Toxoplasma immune responses in pigs. Vaccine. 2008;26:1025-31.

38. Min J, Qu D, Li C, Song X, Zhao Q, Li XA, et al. Enhancement of protective immune responses induced by Toxoplasma gondii dense granule antigen 7 (GRA7) against toxoplasmosis in mice using a prime-boost vaccination strategy. Vaccine. 2012;30:5631-6.

39. Lourenço EV, Bernardes ES, Silva NM, Mineo JR, Panunto-Castelo A, RoqueBarreira MC. Immunization with MIC1 and MIC4 induces protective immunity against Toxoplasma gondii. Microbes Infect. 2006;8:1244-51.

40. Ismael AB, Dimier-Poisson I, Lebrun M, Dubremetz JF, Bout D, Mevelec MN Mic1-3 knockout of Toxoplasma gondii is a successful vaccine against chronic and congenital toxoplasmosis in mice. J Infect Dis. 2006;194:1176-83.

41. Dautu G, Munyaka B, Carmen G, Zhang G, Omata Y, Xuenan X, et al. Toxoplasma gondii: DNA vaccination with genes encoding antigens MIC2, M2AP, AMA1 and BAG1 and evaluation of their immunogenic potential. Exp Parasitol. 2007;116:273-82.

42. Parmley S, Slifer T, Araujo F. Protective effects of immunization with a recombinant cyst antigen in mouse models of infection with Toxoplasma gondii tissue cysts. J Infect Dis. 2002;185(Suppl. 1):S90-5.

43. Nielsen HV, Di Cristina M, Beghetto E, Spadoni A, Petersen E, Gargano N. Toxoplasma gondii: DNA vaccination with bradyzoite antigens induces protective immunity in mice against oral infection with parasite cysts. Exp Parasitol. 2006;112:274-9.

44. Hiszczyńska-Sawicka E, Akhtar M, Kay GW, Holec-Gasior L, Bickerstaffe R, Kur J, et al. The immune responses of sheep after DNA immunization with, Toxoplasma gondii MAG1 antigen-with and without co-expression of ovine interleukin 6. Vet Immunol Immunopathol. 2010;136:324-9.

45. Ahmadpour E, Sarvi S, Hashemi Soteh MB, Sharif M, Rahimi MT, Valadan R, et al. Enhancing immune responses to a DNA vaccine encoding Toxoplasme gondii GRA14 by calcium phosphate nanoparticles as an adjuvant. Immunol Lett. 2017:185:40-7.

46. Beghetto E, Buffolano W, Spadoni A, Del Pezzo M, Di Cristina M, Minenkova $\mathrm{O}$, et al. Use of an immunoglobulin $\mathrm{G}$ avidity assay based on recombinant antigens for diagnosis of primary Toxoplasma gondii infection during pregnancy. J Clin Microbiol. 2003:41:5414-8.

47. Costa JG, Duré AB. Immunochemical evaluation of two Toxoplasma gondil GRA8 sequences to detect acute toxoplasmosis infection. Microb Pathog. 2016;100:229-36

48. Pfrepper Kl, Enders G, Gohl M, Krczal D, Hlobil H, Wassenberg D, et al. Seroreactivity to and avidity for recombinant antigens in toxoplasmosis. Clin Diagn Lab Immunol. 2005;12:977-82.

49. Wasmuth JD, Pszenny V, Haile S, Jansen EM, Gast AT, Sher A, et al. Integrated bioinformatic and targeted deletion analyses of the SRS gene superfamily identify SRS29C as a negative regulator of Toxoplasma virulence. MBio. 2012;3:e00321-12

\section{Ready to submit your research? Choose BMC and benefit from:}

- fast, convenient online submission

- thorough peer review by experienced researchers in your field

- rapid publication on acceptance

- support for research data, including large and complex data types

- gold Open Access which fosters wider collaboration and increased citations

- maximum visibility for your research: over $100 \mathrm{M}$ website views per year

At BMC, research is always in progress.

Learn more biomedcentral.com/submissions 